\title{
REFLEXÕES ACERCA DA PRÁXIS DOCENTE NO CONTEXTO DO ENSINO MÉDIO INTEGRADO NA MODALIDADE EDUCAÇÃO DE JOVENS E ADULTOS
}

\author{
Aldo Rezende ${ }^{2}$ \\ Bruno dos Santos Prado Moura ${ }^{3}$ \\ Maria José de Resende Ferreira ${ }^{4}$
}

\section{RESUMO}

O artigo explicita os desafios da práxis docente evidenciadano Programa Nacional de Integração da Educação Profissional com a Educação Básica de Nível Médio na Modalidade de Educação de Jovens e Adultos (Proeja) no Instituto Federal do Espírito Santo (Ifes) Campus Vitória. Contextualiza o momento atual marcado pela imposição da contrarreformado ensino médio, materializada na Lei no 13.415 de 16/02/2017 epor meio da apropriação dos aportes da pesquisa documental (HELDER, 2006), explora, pontualmente, as experiências do Proeja, em específico, do Curso Técnico em Guia de Turismo Integrado ao Ensino Médio na modalidade de Jovens e Adultos.Além da pesquisa bibliográfica e virtual, foram utilizados relatórios de atividades desenvolvidas junto aos estudantes do Proeja e que serviram de instrumentos para as análises e referências para a devida compreensão acerca da práxis docente. São experiências articuladas no campo do ensino, pesquisa e extensão que estreitam as relações comunidade, mundo do trabalho, práticas políticas e culturais. Essas dimensões interligadas,indicam a perspectiva da consolidação da relação indissociável escolasociedade, promovem o protagonismo estudantil e ressignificam o movimento de resistência e de compromisso histórico com a luta pelo ensino público e de qualidade para aqueles que vivem do trabalho.

Palavras chave: Práxis; Proeja; resistência.

\begin{abstract}
The article explains the challenges of teacher evolution of the National Program for the Integration of Vocational Education with Basic Education for Secondary Education in Youth and Adult Education (Training) at Campus Vitória of the Federal Institute of Espírito Santo (Ifes). To contextualize the present moment for the imposition of

\footnotetext{
${ }^{1}$ Uma versão preliminar desse texto foi apresentado no Seminário Nacional do Ensino Médio Integrado organizado pelo Conselho Nacional de Reitores dos Institutos Federais de Educação, Ciência e Tecnologia, realizado em Brasília nos dias 19 a 21/09/2017.

${ }^{2}$ Professor do Curso Técnico em Guia de Turismo do Ifes.

${ }^{3}$ Coordenador e professor do Curso Técnico em Guia de Turismo do Ifes.

${ }^{4}$ Professora do Curso Técnico em Guia de Turismo e Coordenadora do Proeja.
} 
secondary education, materialized in Law $\mathrm{n}^{\circ} 13.415$ of $02 / 16 / 2017$ and through the appropriation of the sports of documentary research (HELDER, 2006), explores, in a specific way, the experiences of Proeja, in specific, of the Technical Course in Tourism Guide Integrated to High School and Youth. In addition, bibliographical and virtual research were built along the course on teaching praxis. Experiences in the field of education, research and the extent to which communities have, the world of work, political and cultural practices. These dimensions are interconnected, indicate a perspective of consolidation of the school-society relationship, promote the protagonism, study and resignify the movement of resistance and history with a struggle for the public and quality for those who live at work.

Keywords: Praxis; Proeja; Resistance.

\section{INTRODUÇÃO}

$\mathrm{O}$ artigo tem como pretensão trazer uma reflexão sobre os desafios da práxis docente no Programa Nacional de Integração da Educação Profissional com a Educação Básica de Nível Médio na Modalidade de Educação de Jovens e Adultos (Proeja) no Instituto Federal do Espírito Santo (Ifes) Campus Vitória.

$\mathrm{Na}$ atualidade, para pautar uma discussão sobre a modalidade de Educaçãode Jovens e Adultos (EJA) faz-se necessário denunciar a complexidade da política neoliberal que vem sendo reorquestrada a partir do golpe político, jurídico e midiático em curso no país desde o ano de $2016^{5}$. Este projeto, traz no seu bojo, ações de desmonte das políticas públicas e sociais, em especial, no campo da educação, apontando para consequentes fissuras na estrutura de organização e de funcionamento das escolas públicas: uma flagrante ameaça à possibilidade de consolidação da escola pública como locus de produção do conhecimento junto à classe trabalhadora.

Tais ameaças exigem de nós educadores, a urgência e necessária demarcação de nossos espaços de movimentação de enfrentamentos e de resistências. Trata-se, portanto, de reafirmar o compromisso político, militante e ético em defesa da educação enquanto direito, voltada para os anseios dos sujeitos jovens e adultos que tiveram por diversos fatores seus processos de escolarização interrompidos e inconclusos.Como afirma Gadotti (2001, p. 86-87): "Educar nessa sociedade é tarefa de partido, isto é, não

\footnotetext{
${ }^{5}$ Sobre o golpe em curso no país desde o ano de 2016 verificar Souza (2017), assim como Santos (2017).
} 
educa para a mudança aquele que ignora o momento em que vive, aquele que pensa estar alheio ao conflito que o cerca".

Assim considerado, é a partir de aspectos relacionados aos fundamentos das práticas educativas de formação profissional no âmbito do ensino médio integrado para os sujeitos da EJA que buscaremos de forma pontual, realizar um movimento reflexivo com base em algumas experiências vivenciadas pelo coletivo de professores por meio desse Programa, especificamente no Curso Técnico em Guia de Turismo Integrado ao Ensino Médio na Modalidade de EJA.

São experiências concretas capazes de servir de alento ao elucidar as possibilidades das práticas de resistências no contexto de um movimento dialético indutor de alternativas para produzir novos sentidos e novos significados no tocante às práticas político-pedagógicas em seu conjunto de relações no âmbito da escola. Para alcançar o objetivo principal apresentado, qual seja, evidenciar a partir das atividades desenvolvidas por professores e estudantes do Proeja, os desafios da práxis em sua possibilidade de promover a reflexão crítica, o protagonismo e o compromisso ético, estético e político com a transformação da realidade.Recorremos às pesquisas bibliográfica e a documental que nos permitirá fundamentar o movimento reflexivo pretendido e dessa forma, dar conta da importância das experiências acumuladas e vivenciadas, em mais de uma década de luta pela afirmação do Proeja no Ifes Campus Vitória.

Assim, na primeira parte do presente artigo, a atenção volta-se para a tentativa de contribuir com a discussão sobre a atuação do trabalhador de ensino em suas práticas político-pedagógicas, em especial sobre a relação entre conteúdo, formação e trabalho.

$\mathrm{Na}$ sequência, serão elencadas algumas possibilidades de reflexão sobre a importante reação e resistência nesse contexto histórico, marcado pela imposição da contrarreforma $^{6}$ do ensino médio, materializadana Lei $\mathrm{n}^{\circ} 13.415$ de 16/02/2017, em especial em relação às escolas públicas, dentre elas, as diversas instituições que

\footnotetext{
${ }^{6}$ Tomamos de empréstimos a ideia defendida por Ferreira (2017) a partir dos estudos de Behring (2003) que problematiza o conceito de reforma a processos regressivos. Ferreira (2017) pauta como retrocesso as mudanças empreendidas na legislação do ensino médio em vigor desde fevereiro de 2017.
} 
compõem a Rede Federal de Educação, Ciência e Tecnologia ${ }^{7}$. Portanto, de forma pontual, nosso intuito é dar visibilidade às experiências do Proeja, desenvolvidas noCurso Técnico em Guia de Turismo Integrado ao Ensino Médio na modalidade de Jovens e Adultos, ofertado pelo Ifes Campus Vitória.

Finalizando, as considerações vislumbram o despertar do fortalecimento da comunidade escolar frente ao desafio de desconstruir o sentido perverso da contrarreforma do ensino médio imposta pelo atual governo usurpador e desta forma, ressignificar o movimento de resistência e de compromisso histórico com a luta pelo ensino público e de qualidade para aqueles que vivem do trabalho.

\section{TEMPOS DE RETROCESSOS E DE RESISTÊNCIAS: NAS CONTRADIÇÕES REAFIRMA-SE O TRABALHO DOCENTE NA PERSPECTIVA EMANCIPATÓRIA}

No âmbito da contrarreforma do ensino médio consubstanciada na Lei $\mathrm{n}^{\mathrm{o}} 13.415$ de 16/02/2017, é presente a perversidade de uma investida estrategicamente afinada com o propósito de moldar e de instituir um novo senso comum em torno das concepções políticas, ideológicas e econômicas de caráter neoliberal. Segundo essa legislação, o mercado se constitui no orientador de toda realização humana, funcionando como o contexto absoluto de desenvolvimento das relações sociais.

Assim propalado, geridas pelas regras do mundo da produção, as relações humanas se pautariam em uma liberdade entendida dentro do espírito humano de sobrevivência e de superação, o qual se alimenta de um processo de afirmação de dualidades assumido como natural e aceitável (GENTILI, 1995). Impõe-se, portanto, a ideia de um darwinismo social que prega a competição como regra e a desigualdade como princípio.

Nessa conjuntura de reafirmação do doutrinário neoliberal, a educação tem sido um dos alvos mais privilegiados. O argumento central pauta-se na qualidade duvidosa,

\footnotetext{
${ }^{7}$ A Rede Federal de Educação Profissional, Científica e Tecnológica foi criada em 29 de dezembro de 2008 foi criada, pela Lei $\mathrm{n}^{\circ}$ 11.892. Composta pelos Institutos Federais de Educação, Ciência e Tecnologia, pelo Centro Federal de Educação Tecnológica Celso Suckow da Fonseca, pelo Centro Federal de Educação Tecnológica de Minas Gerais, pela Universidade Tecnológica Federal do Paraná, pelas antigas Escolas Agrotécnicas Federais, pelas escolas técnicas vinculadas às Universidades Federais e pelo Colégio Pedro II (BRASIL, 2008). Disponível em: http://portal.mec.gov.br/setec. Acesso em 02 de março de 2018.
} 
firmado na ineficiência da escola pública, cuja referência deveria ser a escola privada, competitiva e focada nos princípios da dinâmica da administração gerencialista (ARAÚJO, 2005). Convém observar com atenção o que subjaz a esse discurso. A educação pública, gratuita, laica e de qualidade social é um direito público subjetivo, ou seja, é inerente aos preceitos da cidadania.

A crítica à educação pública promovida pelo discurso neoliberal procura provar que a incapacidade dessa em satisfazer o desejo de qualidade ocorre pelo fato de ela ser permeada em um ideal de igualdade coletiva impossível de se realizar. Para esse discurso, a qualidade só poderá ser alcançada quando a escola pública abandonar esse princípio coletivista e seguir o ideário dos setores econômico-produtivos no plano da competitividade e da meritocracia.

Ademais, essa ideia esconde uma redução do debate sobre educação ao aspecto estritamente econômico e, por conseguinte, uma redução da ideia de cidadão, que deixa de ser sujeito social com direitos a serem garantidos pelo Estado e cuja cidadania precisa ser fundada pelos e nos princípios da justiça e da igualdade. Na perspectiva do discurso neoliberal, a cidadania se faz no âmbito do mercado por meio do consumo de bens e de produtos. Daí a frequente associação entre cidadão e consumidor. A força dessa visão tem sua evidência na descrença de que possam ser articuladas propostas alternativas na construção de uma escola de qualidade para todos.

A Rede Federal de Educação, Ciência e Tecnologia constitui uma realidade formada por escolas relativamente bem estruturadas, com quadro docente de boa formação, com autonomiapedagógica, administrativa e financeira, com processos eleitorais regulares e com boa parcela de protagonismo dos profissionais da educação. Contexto diverso do que encontramos na maioria das instituições públicas estaduais de nível médio. A partir dessa realidade, tem sido comum a suposição de que as condições objetivas oferecidas pelas escolas da Rede Federal, equivalem a uma educação "de qualidade”. No entanto, é preciso interrogar sobre quais concepções de educação perpassam o cotidiano desse espaço educacional, considerando a histórica proximidade com os "setores produtivosem conformidade com os ditames e interesses do capital monopolista. (NEVES, 2005, p. 26-27)". 
De um modo geral, os estudiosos do campo Trabalho e Educação destacam as contradições do papel social da escola pública, particularmente na oferta da Educação profissional $^{8} \mathrm{e}$ as demandas do processo produtivo sob a égide da ordem capitalista. Nessa dimensão, denuncia-se a tendência atual do reforço da dualidade educacional expresso na contrarreforma do ensino médio, em vez de contribuir para superá-la por meio da oferta de programas que têm por princípios pedagógicos a politecnia, tal como objetivam o Programa Ensino Médio Integrado e o Proeja implantados durante o governo democrático-populardurante os períodos de 2003 a 2015. Em outras palavras, é preciso exercer o olhar crítico sobre as condições objetivas das escolas da Rede Federal, no sentido de escapar da armadilha que as associam à pretendida e propalada qualidade da educação.

Partimos, então, da convicção de que a ação docente é uma ação política que, por diversas razões, se faz encharcada de justificativas que apontam para uma paralisia, um enclausuramento da ação em moldes preestabelecidos. E, assim, paralisados por uma concepção estática da educação e do seu contexto histórico, vemos a escola de nível médio atender plenamente a uma formação fragmentada, unilateral e, cada vez mais, seletiva e excludente, em perfeita sintonia com os postulados neoliberais acerca da educação.

Na reconhecida obra intitulada "Memórias do Cárcere", Graciliano Ramos (1998, p. 34)nos oferece, logo nas primeiras páginas, um excelente argumento para refletir sobre essa questão:"Liberdade completa ninguém desfruta: começamos oprimidos pela sintaxe e acabamos às voltas com a Delegacia de Ordem Política e Social, mas, nos estreitos limites a que os coagem a gramática e a lei, ainda nos podemos mexer”.

De fato, pensando com base nas palavras do renomado escritor, não há contexto mais ou menos favorável para a ação política, há apenas $o$ contexto, e ele será sempre atravessado pelas tensões e projetos em disputas. Nesse sentido, o agir político não se refere a uma questão de oportunidade, mas de convicção.

\footnotetext{
${ }^{8}$ A educação profissional técnica de nível médio é uma das três modalidades de educação profissional e tecnológica previstas pela legislação educacional brasileira Sua oferta pode ser "articulada" com o ensino médio (habilitação profissional técnica de nível médio na mesma instituição de ensino com uma única matrícula); "concomitante" (a matrícula pode ocorrer em duas escolas distintas: nível médio e curso profissionalizante) e "subsequente" (para os estudantes que já concluíram o ensino médio).
} 
A práxis docente no ensino médio integrado oferecido pela Rede Federal, em especial nos cursos direcionados aos sujeitos da EJA por meio do Proeja assume, portanto, um caráter dialético. A escola comprometida com a emancipação humana e a formação integral dos sujeitos educandos, não resultará somente de prédios bem equipados, salas climatizadas, bibliotecas com amplo acervo, profissionais bem formados, dentre outras possibilidades.

É notório que esses fatores são importantes no processo de afirmação dessa perspectiva de educação, porém, em si mesmos não conduzirão a esse projeto, que resultará, de fato, da luta política, na qual se contrapõem projetos de formação e de sujeitos. Em outras palavras, as condições objetivas podem levar a um determinado tipo de educação de qualidade, mas é preciso indagar sobre eles criticamente e intervir para provocar o movimento que se pretende.

No âmbito da práxis, o docente, compreendido como agente capaz de dar respostas aos problemas postos pela sociedade e de fazer frente aos desafios do presente (GADOTTI, 2001), deve encontrar, na contemporaneidade do seu agir, as possibilidades para se alcançar um horizonte educativo em que a escola esteja comprometida com a formação humana, com a transformação social capaz de se contrapor à perversa lógica do ideário neoliberal defendido por amplos setores conservadores da sociedade brasileira.

Dessa maneira, a práxis educativa no contexto das instituições da Rede Federal deve ser projetiva no sentido de encontrar as fissuras e as contradições desse sistema e evidenciá-las, além de fecundá-las com o germe da mudança, pois, como destacou Gadotti (2001, p. 105), “a transformação das coisas só é possível porque no seu próprio interior coexistem forças opostas tendendo simultaneamente à unidade e à oposição".

O exemplo das formas de resistência política assumida pelos estudantes de todo o país por ocasião do movimento de ocupação das escolas públicas, ilumina as possibilidades de romper com a letargia para, assim, ressignificar o que precisa ser repensado e assumido enquanto projeto político de vida, reconhecendo-nos a nós mesmos enquanto capazes e imprescindíveis na luta permanente pela liberdade, pela democracia e pela justiça social. 
Com efeito, reconhecer a escola em sua função reprodutora das desigualdades sociais é um importante passo, capaz de nos mover a assumir o papel de intelectuais orgânicos ativos e comprometidos com a produção do conhecimento libertário dos sujeitos, sobretudo os trabalhadores, historicamente alijados do direito à educação enquanto instrumento de formação omnilateral e da integralidade. Neste ínterim, entendemos ser imprescindível manter acesa a chama das discussões e reflexões sobre o cotidiano de nossas práticas sem perder de vista as considerações acerca dos conflitos e tensões dialeticamentereconhecidos e indispensáveis para o alcance da totalidade do movimento reflexivo e compreensão sobre a importância do pensar para saber fazer, acontecer para transformar: práxis.

\section{DUALIDADE ESTRUTURAL E CONTEÚDOS DE ENSINO}

Conforme alguns autores que se dedicam ao estudo do ensino médio (RAMOS, 2004 e 2005; OLIVEIRA, 2009; MOURA, LIMAFILHO, SILVA, 2015; FRIGOTTO, CIAVATTA, 2004 e 2011), há a compreensão de que esta modalidade é atravessada por uma contradição histórica, explicitada pela dualidade estrutural e fragmentação formativa. No movimento de reflexão desta contradição, esboça-se o perfil dual, no qual entram em disputa a formação para a cidadania e a formação para o mercado de trabalho. De acordo com as ponderações de Oliveira (2009. p. 54),

[...] A tentativa de universalizar a articulação entre a formação geral e a formação técnica não conseguiu superar a dualidade histórica que persegue o Ensino Médio, pois as escolas não se estruturaram a partir de um novo princípio educativo, no qual o pensar e o fazer fossem considerados expressões de um único saber constituinte da identidade humana.

Percebemos então, que a questão central colocada e que mobiliza muitos estudiosos do ensino médio interroga sobre o projeto subjacente à modalidade. As contradições de classe que compõem a sociedade brasileira ecoam também nas escolas da Rede Federal e quando trazemos à luz o seu cotidiano, percebemos uma naturalização das relações sociais hegemônicas na atual sociedade capitalista e que valorizam a lógica da competitividade, da submissão, da não ação política. 
Assim considerado, a atual contrarreforma do ensino médio reafirma ainda mais essa lógica perversa de disputa política. Nesse cenário, não podemos perder de vista a importância e necessidade de fortalecer nossa organização para assim, junto com outros movimentos sociais e outras entidades da sociedade civil, contribuir para "constituir um projeto de ensino médio que supere a dualidade entre formação específica e formação geral e que desloque o foco de seus objetivos do mercado de trabalho para a pessoa humana (RAMOS, 2004, p. 40)".

No âmbito da práxis docente, esse desafio lançado por Ramos (2004), perpassa a problematização de um dos pontos fundamentais subjacentes ao meio escolar: os conteúdos de ensino. Predomina nas escolas de ensino médio em geral, e nas escolas da Rede Federal em particular, uma compreensão de conteúdos como saberes estabelecidos e que devem ser transmitidos e posteriormente avaliados. Em geral, essa percepção os vê como conhecimentos exclusivos das matérias ou disciplinas que se expressam em nomes, conceitos, princípios, enunciados e teoremas (ZABALA, 1998). É como se eles fossem coisa em si, totalmente satisfatórias e que trouxessem em si o necessário para a formação dos estudantes em sua totalidade social.

Entendemos que essa ideia em torno dos conteúdos como coisas em si corresponde, ainda que indiretamente, às demandas do capitalismo e suas relações de produção no contexto atual, marcado pelo pragmático aperfeiçoamento da produção a partir do uso de novas tecnologias. Nesse contexto, a mão de obra disponível no mercado não precisa ser eficientemente treinada, mas sim treinável (CIAVATTA, 2009). Como argumentou Ramos (2004, p. 39), essa perspectiva entende que é necessário o desenvolvimento de "competências genéricas e flexíveis, de modo que as pessoas pudessem se adaptar facilmente às incertezas do mundo contemporâneo". Os conteúdos trabalhados em si mesmos atenderiam a esse requisito, pois garantiriam o instrumental - ou competências -, fundamental para que o estudante seja alocado nos postos de trabalho, conforme sua capacidade e seu mérito.

Associada a essa compreensão, está também a noção de que os estudantes precisam desses conteúdos para enfrentar a vida no mercado de trabalho. Atribui-se, assim, um caráter meramente instrumental e pragmático aos conteúdos de ensino, descolando-os de qualquer possibilidade formativa omnilateral. $\mathrm{O}$ caráter classista da 
escola média se mostra na sua crueza exatamente nos cálculos de rendimento dos estudantes, quando se mede o quanto de conteúdo ele sabe, ou melhor, foi capaz de processar. O foco, portanto, não está no sujeito em formação, mas sim nos conteúdos transmitidos para a sua moldagem e formatação para o atendimento à perspectiva mercantil. A associação entre quantidade de conteúdo e formação, nos parece, responder a um tipo de sociedade e a um tipo de demanda social, qual seja, cujos sujeitos adaptados aos caprichos e as exigências do mercado, do trabalho pelo trabalho.

Entendemos que essa percepção oblitera o caráter sócio-histórico dos conteúdos e aprisionam-nos em formas fixas de difusão. Esse aspecto instrumental a que nos referimos acima está de acordo com uma perspectiva reducionista dos conteúdos de ensino, vistos estritamente no seu aspecto disciplinar e cognitivo (ZABALA, 1998). Em uma crítica a pedagogia das competências, Ramos (2005, p. 115) enfatiza que a finalidade da formação consiste em "possibilitar às pessoas compreenderem a realidade para além da sua aparência fenomênica". Nesta defesa, os conteúdos não têm caráter meramente instrumental. Eles estão vinculados a uma proposta de emancipação humana:

Apreender o sentido dos conteúdos de ensino implica em reconhecêlos como conhecimentos construídos historicamente e que se constituem, para o trabalhador, em pressupostos a partir dos quais se podem construir novos conhecimentos no processo de investigação e compreensão do real (RAMOS, 2005, p. 108).

Os conteúdos, portanto, devem ser aportes para uma formação humana integral, que nos possibilite alcançar as diversas dimensões do ser humano: cognitiva, política, cultural, afetiva, psicomotora, de relações de vida em sociedade pautada por contradições historicamente estabelecidas. O conhecimento pressupõe um solo de relações sociais, que por sua vez são atravessadas pelas relações de poder (SEVERINO, 1998). Ao assumir um caráter instrumental, os conteúdos de ensino - que nada mais são do que formas assumidas pelo conhecimento socialmente produzido para atender as demandas escolares - parecem se descolar do seu contexto e assumir uma autonomia que, no contexto da sociedade capitalista neoliberal, atende aos interesses dos grupos 
socialmente privilegiados, reafirmando as estratégias de controle social dos detentores dos espaços de poder.

A importância de se alargar a compreensão dos conteúdos de ensino significa entender a educação como uma prática ao mesmo tempo técnica e política, devendo ser essa, na defesa de Severino (1998, p. 36) "atravessada por uma intencionalidade teórica, fecundada pela significação simbólica", sem, no entanto, perder de vista a importante mediação com "a integração dos sujeitos educandos nesse tríplice universo das interlocuções existenciais: no universo do trabalho, da produção material, das relações econômicas" continua ponderando o autor (1998, p. 36). Cabe reafirmar a citada integração "no universo das mediações institucionais da vida social, lugar das relações políticas, esfera do poder; no universo da cultura simbólica, da experiência da identidade subjetiva, esfera das relações intencionais (SEVERINO, 1998, p. 36)".

Em outras palavras, os conteúdos são sim, formas assumidas pelo conhecimento cientificamente produzido, mas são também - e ao mesmo tempo -, produções culturais e históricas, resultado de convenções e seleções e estão permeados de cargas valorativas. Não são, portanto, neutros. Há um aspecto ético nessa discussão, muito bem colocado por Gramsci (1968, p. 119) ao discutir o papel da cultura geral na formação dos indivíduos:

Coloca-se a questão de modificar a preparação do pessoal técnico político, integrando sua cultura de acordo com as novas necessidades, e de elaborar novos tipos de funcionários especializados, que integrem - sob forma colegiada - a atividade deliberativa. O tipo tradicional do 'dirigente' político, preparado apenas para as atividades jurídicoformais, torna-se anacrônico e representa um perigo para a vida estatal: o dirigente deve ter aquele mínimo de cultura geral que lhe permita, senão 'criar' autonomamente a solução justa, pelo menos saber julgar entre as soluções projetadas pelos especialistas e, consequentemente, escolher a que seja justa do ponto de vista 'sintético' da técnica política.

É preciso dessa forma indagar: a que servem os conteúdos ensinados na escola de nível médio? Essa não é uma questão trivial. Somos levados cotidianamente a supor que o destino dos nossos estudantes está definido. Irão se formar no ensino médio, serão absolvidos ou não pelo mundo do trabalho ou prestarão o Exame Nacional do Ensino 
Médio e ingressarão em alguma das universidades brasileiras, da qual sairão formados para o exercício de uma profissão qualquer.

Tal perspectiva limita a práxis docente a simples transmissão dos conteúdos necessários para que o estudante galgue com sucesso esses degraus e se torne uma pessoa "bem-sucedida". Assim, faz-se necessário outro exercício de reflexão crítica. Se os conteúdos são o bastante para formar o estudante, como nos portaríamos diante de um estudante de nível médio que, tendo estudado toda a história do Brasil e tendo conhecimento do processo escravocrata pelo qual passou nossa sociedade, manifeste opiniões racistas envolvendo, por exemplo, a política de cotas para acesso às universidades? Qual seria nossa reação diante da atitude de um médico que, tendo estudado tudo o que se refere a ética na sua conduta profissional, receita um remédio sem nenhum efeito " tal como placebo" para seus pacientes, apenas para alcançar a meta de vendas do laboratório produtor do medicamento e ganhar uma viagem para a Europa? Imaginemos que um jovem estudante de Direito, depois de formado, siga a carreira de juiz e de forma declaradamente parcial promova o fim do Estado Democrático de Direito através de práticas coercitivas e o abuso de autoridade sob o crivo dos holofotes da grande mídia? Ou mesmo, enverede pelo campo da política e, ao se tornar parlamentar, passe a defender medidas restritivas às liberdades civis e aos direitos sociais?

Sabemos que o processo de aprendizagem não é limitado apenas à relação professor-aluno. Mas essas situações hipotéticas nos ajudam a desconstruir a suposta neutralidade dos conteúdos de ensino e inserir na ordem do dia a problematização sobre os tipos de pessoas que formaremos em nossas escolas. De alguma forma temos responsabilidades que se concretizam em manifestações de alegrias, tristezas ou frustrações.

Acreditamos que os conteúdos devem ser pensados e trabalhados no âmbito da relação tripartite entre Trabalho, Ciência e Cultura (RAMOS, 2004; FRIGOTTO, CIAVATTA, 2004). Nessa relação, que não é linear, cada dimensão interfere no outro diretamente. O trabalho, como mediação de primeira ordem do ser humano com o meio natural, permite a ele objetivar esse mundo, atribuindo-lhe sentido e significado. Trabalho e cultura, assim, são indissociáveis e, a partir deles, torna-se possível 
aexplicação sistematizada do mundo, na forma de ciência. Essa, por sua vez, possibilita novas formas de trabalho e de cultura. Como manifestação da ciência, os conteúdos de ensino são também cultura, pois exprimem o legado da sociedade, aquilo que ela considera relevante preservar e difundir. Evidenciam, nesse sentido, uma sistematização que manifesta um olhar pedagógico. Resultam, portanto, de trabalho. Se hoje eles servem a uma lógica de competição e desigualdade que se retroalimenta e se perpetua a partir da escola, é preciso mexer as peças, provocar fissuras, inverter a lógica, fazendo-a movimentar em favor de uma formação voltada para a pessoa e para a vida em uma sociedade justa e igualitária.

Dessa forma, na tentativa de diálogo entre conteúdos e realidade vivida e vivenciada pelos estudantes e a relação desse diálogo com a perspectiva de formação onmilateral, capaz, portanto, de afirmar o trabalho enquanto princípio educativo, apresentamos, na sequência, a exposição de experiências pontuais, desenvolvidas no âmbito do Proeja do Ifes Campus Vitória. Elas são mostradas na condição de alento e de possibilidades no campo da resistência necessária frente aos desafios impostos pela contrarreforma de ensino médio em curso nas escolas do país.

\section{EXPERIÊNCIAS DE INTEGRAÇÃO DE ENSINO, PESQUISA E EXTENSÃO: DESAFIOS DA PRÁXIS DOCENTE}

Dentre oscampi do Instituto Federal implantados no Espírito Santo, o de Vitória se destaca ao oferecer diversos cursos na modalidade de EJA. Desta forma, importante problematizar os desafios enfrentados ao longo de mais de uma década, numa instituição de ensino de perfil majoritariamente elitista (OLIVEIRA; PINTO, 2012), declaradamente comprometida com a formação unilateral, com foco nas expectativas do mercado de trabalho. Constatamos, nesse cenário, que a contrarreforma do ensino médio imposta tenciona ainda mais as relaçõesconcernente ao acesso à educação pública de qualidade sinalizando para o comprometimento do projeto político pedagógico de formação omnilateral, assim como das condições necessárias à garantia da equidade no acesso, permanência e êxito dos estudantes do Proeja.

Nesta perspectiva, importa não perder de vista a voracidade dos processos de dominação econômica, política e ideológica no viés dos princípios neoliberais 
alicerçados nas e pelas mais diversas estratégias de exploração e controle social das classes populares que vivem do trabalho. São trabalhadores e trabalhadoras, há muito alijados(as) do projeto de crescimento econômico dos grupos dominantes, pautado na exacerbada concentração de renda e riquezas, (a qual também foi) possibilitada pelo movimento, por vezes antidemocrático, de controle das esferas de decisão e poder político.

Não por acaso, a conjuntura política desvelada a partir do impeachment da presidenta Dilma Rousseff em 2016, iluminou a possibilidade de compreensão sobre as estratégias para garantir reformas de interesse das corporações empresariais, financeiras e rentistas. Assim, assistimos a imposição da contrarreforma do ensino médio dentro deste contexto marcado tanto pela anulação das iniciativas de projeção política e econômica do país no cenário mundial, como também pelo desmonte das políticas sociais delineadas desde 2003, implementadas pelos governos petistas: fomentados e protagonizados pelos mais diversos movimentos sociais, sindicatos, associações acadêmicas e científicas, entre outros representantes da sociedade civil.

Os impactos da contrarreforma do ensino médio são assustadores e por isso, fazse necessário reiterar o papel dos educadores enquanto intelectuais orgânicos, dentro das suas possibilidade e compromisso histórico de reafirmarem os interesses contraditórios de classe e assim então, fazer valer o movimento contra hegemônico de transformação social. Neste contexto, as experiências em curso no Proeja do Ifes campus Vitória se constituem a partir das considerações sobre as singularidades de um público formado por jovens e adultos em grande parte trabalhadores e desempregados, historicamente marcados pela dominação e exploração de toda ordem.

Sem perder de vista e, desde já, reconsiderando o caráter antidemocrático e coercitivo da contrarreforma do ensino médio e seus impactos no conjunto das transformações impostas pela classe dominante a partir do golpe de Estado de 2016, desconstruir o movimento de letargia e desesperança se impõe como importante lenitivo. A escola, embora, em muitos casos reprodutora das desigualdades sociais, conforme já denunciada, é território de disputa política e de poder. Sendo assim, necessário se faz repensar insistentemente o papel da escola. Escola para quem? Educação para o trabalho, ciência, cultura e tecnologia a serviço de quem? Essas são 
algumas das inúmeras questões que precisamos sempre refletir para dar conta de nos situarmos e entendermos a dinâmica do nosso papel de educadores, intelectuais orgânicos comprometidos com outro projeto de sociedade.

Nessa perspectiva, para melhor alcançar o significado das experiências realizadas no âmbito da modalidade de educação de jovens e adultos, mais especificamente noCurso Técnico em Guia de Turismo Integrado ao Ensino Médio na modalidade da EJA, no Ifes Campus Vitória, importante se faz dar conta da possibilidade de integração entre ensino, pesquisa e extensão como saída estratégica para a compressão políticopedagógica imposta no âmbito da contrarreforma do ensino médio. Levar o estudante a organizar as ideias a partir do cotidiano das relações sociais estabelecidas em suas relações com o conteúdo das disciplinas, enquanto, cimento do processo de reflexão, é sem sombra de dúvidas, romper com a "zona de conforto" do pensamento alienado e da postura "docilizada" e "cordial” para, a partir do conflito deflagrado, tornar possível um outro olhar e uma outra leitura da realidade. Não se trata de uma receita, pronta e acabada, uma vez que oeducador precisa estar comprometido e atento para as possibilidades do movimento do pensamento do estudante em seu peculiar movimento de organização das ideias. Em outras palavras, esse exercício de construção do conhecimento é possível por meio de práticas pedagógicas alicerçadas em projetos integrados de ensino, pesquisa e extensão. Em muitos dos casos, trata-se de uma oportunidade de romper com a falsa compreensão de que a escola é uma "bolha', uma ilha dissociada do arquipélago: a sociedade em sua totalidade.

Por meio das práticas pedagógicas alicerçadas nas fissuras existentes, tanto nos conteúdos programáticos como nas possibilidades de ações interdisciplinares, ao educador é possível "se mexer", sair das armadilhas perversas, impostas pela atual normatização do ensino médio, principalmente se levado em consideração a proposta de precarização do ensino e do "patrulhamento" ideológico imposto pela lei do pensamento únicoimplícito do projeto "escola sem partido"9

Desse modo, muitas experiências no campo das práticas pedagógicas, além da possibilidade de integrar conteúdos, possibilita também a contextualização que precisa estar presente no dinâmico processo de construção do conhecimento. A título de

${ }^{9}$ Projeto de Lei no 867/2015, que cria o Programa Escola Sem Partido. Importante contribuição analítica sobre esse projeto de lei pode ser encontrada emFrigotto (2017). 
exemplo concreto, uma coisa é exaltar a transposição do meio natural ao meio técnico científico-informacional, sem, contudo, compreender e apreender a historicidade da complexidade que perpassa por esse processo de evolução cientifico-cultural e tecnológico. Ainda no âmbito da exemplificação, parafraseando as considerações de Fernandes (2008, p.48), é preciso compreender e apreender que:

Da escravidão à colheitadeira controlada por satélite, o processo de exploração e dominação está presente, a concentração da propriedade da terra se intensifica e a destruição do campesinato aumenta. $\mathrm{O}$ desenvolvimento do conhecimento que provocou as mudanças tecnológicas foi construído a partir da estrutura do modo de produção capitalista. De tal maneira que houve o aperfeiçoamento do processo, mas não a solução dos problemas socioeconômicos e políticos, o latifúndio efetua a exclusão pela improdutividade, e o agronegócio promove a exclusão pela intensa produtividade.

O desafio das experiências no campo das vivências pedagógicas precisa ser enfrentado com seriedade e comprometimento capaz de irromper contra o reducionismo da proposta de ensino instrumental e pragmático a serviço dos interesses do capital, haja vista asua capacidade de gerar desigualdades e injustiças sociais. Promover ações capazes de estreitar as relações escola-comunidade, escola-mundo do trabalho, escolamundo das práticas políticas, escola-mundo da cultura, escola-mundo da tecnologia é com certeza, consolidar a relação indissociável escola-sociedade. Para tanto, o exercício de contextualizar fatos, fenômenos, situações, dentre outras possibilidades de reflexão crítica, é sem sombras de dúvida, possibilitar aos estudantes o exercício crítico de organização das ideias e movimento do pensamento comprometido com a luta de classes.

Por meio dos programas e projetos, na dimensão do ensino, pesquisa e extensão, a nós educadores comprometidos com a organicidade do projeto de escola em sua totalidade social, sempre será possível "se mexer". É nestas possibilidades que a nós educadores, será sempre possível usar a criatividade, os saberes e o conhecimento, a astúcia e o rigor científico do pensar para saber fazer, de forma participativa e compartilhada, promovendo assim o protagonismo de nossos estudantes na condição de sujeitos engajados em experiências didático-pedagógicas possíveis, principalmente no exercício do diálogo permanente. Como apontado por Freire (1985, p.34), “o que se 
pretende com o diálogo" sem dúvida, “[...] é a problematizarão do próprio conhecimento em sua indiscutível reação com a realidade concreta na qual se gera e com a qual incide para melhor compreendê-la, explica- lá e transformá-la”.

Com certeza, a resistência se concretiza por meio da práxis enquanto possibilidade de enfrentamentos, de estabelecer movimentos contra hegemônicos na perspectiva dos conflitos e das contradições postas. No campo das relações entre ensino, pesquisa e extensão, um exercício à concretude dessa relação revela-se a partir das possibilidades da metodologia da pesquisa-ação, explorando seu objetivo principal que deve ser "direcionar a nossa ação para a conscientização dos envolvidos e sempre tendo em mente conhecer a realidade para transformá-la (BASTOS E MION, 2001, p.31)”. Nesseperspectiva, é necessária a participação dos envolvidos em todos os momentos das etapas da proposição em foco: planejamento, ação, observação, avaliação para o replanejamento.

As experiências a seguir apresentadas são pontuais na medida que fazem parte de um dinâmico processo de resistência no campo das ações político-pedagógicas indispensáveis à incansável luta de buscar contrapor ao projeto hegemônico de escola pela escola; formação para o mercado; escola do pensamento único, além de outros interesses nefastos contidos nas falácias dos arautos da contrarreforma do ensino médio e das reformas trabalhista e da previdência e outras medidas de austeridade.

No âmbito dos princípios que consolidam os fundamentos da modalidade de educação de jovens e adultos, a iniciativa de elaboração participativa do programa de extensão denominado Coletivo pela base: educação e mobilização para o exercício da cidadania, aponta para o comprometimento dos educadores que, na condição de intelectuais orgânicos, buscam na elaboração e implementação de projetos específicos, possibilitar o diálogo entre escola e comunidade sob a intermediação e participação direta dos estudantes. Outrossim, os projetos de pesquisa em nível de iniciação científica júnior voltados para a identificação e caracterização dos espaços e grupos afrodescendentes, assim como a identificação e caracterização das comunidades populares da cidade de Vitória/ES, são possibilidades para o exercício do diálogo interdisciplinar entre conteúdo das mais diversas disciplinas de conhecimentos gerais e do núcleo técnico do Curso Técnico em Guia de Turismo. 
O projeto embrionário de organização e realização da I Semana de Turismo do Ifes Campus Vitória, realizada no ano de 2016, permitiu reconhecer o protagonismo dos estudantes do Curso Técnico em Guia de Turismo em todos os processos que culminaram com as discussões sobre o tema: Turismo e Hospitalidade na diversidade. Discussões polêmicas sobre xenofobia, homofobia, misoginia, preconceitos de classe, racismo, assim como sobre os princípios da democracia, da ética e da hospitalidade foram devidamente estudados e debatidos pelo conjunto dos estudantes durante o citado evento. A partir de então, os estudantes representados em comissões junto aos docentes, passaram a movimentar-se para a realização da II Semana do Turismo com o tema: limites e desafios da formação e atuação profissional dos guias de turismo no Espírito Santo, oportunidade em que também aconteceu a I Feira de Turismo do IfesCampus Vitória, organizada pelos estudantes em conjunto com docentes no ano de 2017.

No âmbito da modalidade EJA, outra experiência diz respeito ao projeto de extensão denominado Mobiliza Proeja, que se propõe a promover a equidade das condições de acesso dos jovens e adultos ao Ensino Médio Integrado do Ifes. Ações de incursão nas comunidades com parcerias estabelecidas entre movimentos sociais, sindicatos, ONGs e prefeituras do entorno da capital, buscam divulgar e criar efetivas condições de acesso à escola.

O projeto de ensino médio integrado na modalidade EJA realizado no IfesCampus Vitória, persegue a proposta de formação onmilateral dos estudantes. Trata-se, portanto, de um projeto político comprometido com iniciativas de promoção humana e emancipação cidadã. Pegar na mão, olhar nos olhos, fazer a escuta, driblar os limites do processo de aprendizagem marcado pelos fracassos vivenciados, são práticas indispensáveis a educadores que se permitem orgânicos no processo de desconstrução do processo de dominação e exploração das classes populares.

Assim, os conteúdos integrados em permanente diálogo com a realidade do educando sinalizam para a possibilidade de fermentar o movimento histórico de resistência no enfrentamento aos desafios por meio de um projeto político pedagógico que busca reduzir as tensões presentes na estrutura do ensino médio integrado em suas contradições historicamente determinadas. 


\section{CONSIDERAÇÕES FINAIS}

A discussão sobre os desafios da proposta de ensino médio integrado hoje passa necessariamente pelas considerações acerca do movimento de desmonte das políticas públicas e sociais, assim como, pelos impactos da crise econômica e política agravada a partir do impeachment deDilma Rousseff. Além do crescente índice de desemprego, o movimento de desqualificação do país no âmbito do cenário político e econômico internacional são fatores que precisam ser considerados em suas correlações com as reformas em curso: trabalhista, previdenciária e da educação.

Em especial, na contrarreforma do ensino médio imposta, arbitrariamente, as imposições de uma matriz curricular e da redistribuição da carga horária das disciplinas comprovam a estratégica de intervenção em dois campos de disputas políticas na totalidade do projeto político pedagógico em processo a partir de 2006, quando da instituição do ensino técnico integrado nas escolas de ensino médio do país. Declaradamente é possível dar conta do movimento induzido de paulatina desintegração entre ciência, trabalho, tecnologia e cultura.

A partir da referida estratégia contida no projeto de contrarreforma do ensino médio em curso, a proposta de formação unilateral do estudante afirma-se na condição antidemocrática de uma escola cuja finalidade é preparar de forma seletiva e diferenciada os estudantes de acordo com o lugar que oesses deverão ocupar na sociedade, reafirmando, mais uma vez a dualidade da educação brasileira.

Neste cenário conjuntural marcado por rupturas e descontinuidades, o papel dos educadores precisa ser repensado no âmbito da compreensão e da definição de estratégias de enfrentamento aos desafios que se tornaram ainda maiores e complexos. Em particular, a modalidade de educação de jovens e adultos torna-se ainda mais preocupante quando levado em consideração os desafios inerentes aos processos de acesso, permanência e êxito cada vez mais comprometidos, considerando o fechamento das escolas de EJA em toda região capixaba, a diminuição dos recursos da assistência estudantil, entre outras medidas tomadas a curto e médio prazo. Entretanto, mesmo diante desse quadro apontado, "práticas de resistências" (OLIVEIRA; FERREIRA, 2018) são empreendidas no Proeja do Ifes Campus Vitória e desvelam que os processos exitosos de escolarizaçãovivenciados pelos discentes do Proeja avançam à medida que 
ocupam esses espaços e, diante dessas demandas sociais, novos cursos são implantados, a exemplo do Técnico em Guia de Turismo e em Hospedagem. Esses movimentos que evidenciam "marcas de resistências", anunciadas por Oliveira e Ferreira (2018), reconfiguram a inserção orgânica da modalidade no âmbito da instituição, reafirmam a luta permanente em defesa da justiça e ética (FREIRE, 2010) e sinalizam para os significados de propostas educativas, comprometidas com a reflexividade sobre a práxis em sua capacidade de perseguir a proposta de formação integral e transformação da realidade do educando e por conseguinte do próprio educador.

Pensar a escola em sua relação com a totalidade social coaduna com as estratégias de enfrentamento ao movimento da escola do pensamento único a serviço dos interesses exclusivos de reprodução do capital na (i)lógica da exploração e da espoliação das classes populares, há muito alijadas de seus direitos elementares.

Contudo, é a partir do reconhecimento das estratégias perversas da contrarreforma do ensino médio em vigor, que à nós educadores, cabe o histórico compromisso de inibir o movimento de naturalização e banalização do saber e dos conhecimentos contextualizados e sistematizados a partir da escola em sua relação indissociável com o mundo, com a sociedade em sua totalidade. Desta forma, construiremosa possibilidade de avançar na promoção dos estudantes enquanto protagonistas capazes de organizar as ideias e movimentar o pensamento crítico sobre a realidade de vida.

As possibilidades de avanço afirmam-se a partir de movimentos de resistências articulados no âmbito da tomada de consciência, organização e mobilização da comunidade escolar no sentido de lutar pela manutenção do Estado de Direito, da liberdade de pensar e expressar e pela garantia do direito à educação pública e de qualidade socialmente reconhecida. 


\section{BIBLIOGAFIA}

ARAÚJO, Gilda Cardoso de.; OLIVEIRA, Romualdo Portela de. Qualidade do ensino: uma nova dimensão da luta pelo direito a educação. Revista Brasileira de Educação. Rio de Janeiro, n. 28, Jan/ Fev/ Mar/ Abr, 2005. p. 5-24.

CIAVATTA, Maria. Mediações históricas de trabalho e educação: gênese e disputas na formação dos trabalhadores. Rio de Janeiro: Lamparina, CNPq, Faperj, 2009.

FERNANDES, Bernardo Mançano. Educação do Campo e território camponês no Brasil. In: Educação do Campo: campo - políticas - educação. SANTOS, Clarice Aparecida dos. (Org.) Brasília: MDA, 2008, p.39-66.

FERREIRA, Eliza B., A contrarreforma do Ensino Médio no contexto da nova ordem e progresso.Educ. Soc., Campinas, v. 38, no. 139, p.293-308, abr.-jun., 2017.

FREIRE, Paulo. Extensão ou comunicação. Rio de Janeiro: Paz e Terra. $8^{\text {a }}$ ed. 1985.

Paulo. Pedagogia da Indignação - cartas pedagógicas e outros escritos. São Paulo: Editora UNESP, 2000.

FRIGOTTO, Gaudêncio. CIAVATTA, Maria (orgs.). Ensino Médio: ciência, cultura e trabalho. Brasília: MEC, SEMTEC, 2004.

FRIGOTTO, Gaudêncio(org.). Escola "sem" partido: a esfinge que ameaça a educação e a sociedade brasileira. Rio de Janeiro: UERJ, LPP, 2017.

GADOTTI, Moacir. Pedagogia da práxis. São Paulo: Cortez: Instituto Paulo Freire, 2001.

GENTILI, Pablo. Adeus à escola pública: a desordem neoliberal, a violência do mercado e o destino da educação das maiorias. In: (org.). Pedagogia da exclusão: crítica ao neoliberalismo em educação. $4^{\text {a }}$ ed. Petrópolis: Vozes, 1995. p. 228 252.

GRAMSCI, Antonio. Os intelectuais e a organização da cultura. Rio de Janeiro: Editora Civilização Brasileira, 1968.

HELDER, R. R. Como fazer análise documental. Porto, Universidade de Algarve, 2006.

MION, Rejane Aurora. SAITO, Carlos Hiroo. Investigação ação: mudando o trabalho de formar professores. Ponta Grossa: Gráfica Planeta, 2001.

MOURA, Dante Henrique; LIMA FILHO, Domingos Leite; SILVA, Mônica Ribeiro. Politecnia e formação integrada: confrontos conceituais, projetos políticos e 
contradições históricas da educação brasileira. Revista Brasileira de Educação, Rio de Janeiro, v. 20, n. 63, out.-dez., 2015. p. 1057-1081.

NEVES, L.M.W. (Org.). A nova pedagogia da hegemonia: estratégias do capital para educar o consenso. São Paulo: Xamã, 2005.

OLIVEIRA, Edna C. de; PINTO, Antonio H. O percurso do proeja/ES: conflitos, desafios e proposições. In: OLIVEIRA, Edna C. de; PINTO, Antonio H.; FERREIRA, Maria José de Resende. EJA e Educação Profissional: desafios da pesquisa e da formação no Proeja. Brasília: Liber Livro, p.13 - 41, 2012.

OLIVEIRA, Edna C; FERREIRA, M. J. de Resende. Políticas de EJA: Percursos de Escolari- zação, de Profissionalização e de Resistência no Proeja. Revista Trabalho Necessário, ano 16 - n. 30/2018. p. 43-66.

OLIVEIRA, Ramon de. Possibilidades do Ensino Médio Integrado diante do financiamento público da educação. Educação e Pesquisa. São Paulo, v. 35, n. 1, p. 5166, jan./ abr. 2009. p. 51-66.

RAMOS, G. Memórias do Cárcere.Ed Record.1998.

RAMOS, Marise. Possibilidades e desafios na organização do currículo integrado. In: FRIGOTTO, Gaudêncio. CIAVATTA, Maria (orgs.). Ensino médio integrado: concepção e contradições. São Paulo: Cortez Editora, 2005. p.107-128.

. O projeto unitário de ensino médio sob os princípios do trabalho, da ciência e da cultura. In: FRIGOTTO, Gaudêncio. CIAVATTA, Maria (orgs.). Ensino Médio: ciência, cultura e trabalho. Brasília: MEC, SEMTEC, 2004. p. 37-52.

SANTOS, Wanderley Guilherme dos. A democracia impedida: o Brasil no século XXI. Rio de Janeiro: FGV Editora, 2017.

SEVERINO, Antônio Joaquim. O conhecimento pedagógico e a interdisciplinaridade: o saber como intencionalidade da prática. In: FAZENDA, Ivani (org.). Didática e interdisciplinaridade. Campinas, SP: Papirus, 1998. P. 31- 44.

SOUZA, Jessé. A elite do atraso: da escravidão à Lava Jato. Rio de Janeiro: Leya, 2017.

ZABALA, Antoni. A prática educativa: como ensinar. Porto Alegre: Artmed, 1998. 